\title{
Superior Mesenteric and Portal Vein Reconstruction With Cadaveric Allograft During Pancreatoduodenectomy - A Case Report and Literature Review
}

\author{
NICOLAE BACALBASA ${ }^{1,2,3^{*}}$, IRINA BALESCU ${ }^{4}$, MIHAELA VILCU $^{1,5}$, SIMONA DIMA $^{3}$,

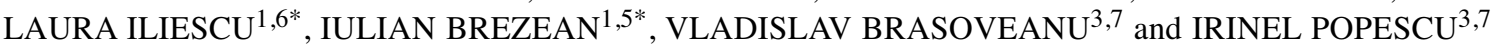 \\ 1 "Carol Davila" University of Medicine and Pharmacy, Bucharest, Romania; \\ ${ }^{2}$ Department of Obstetrics and Gynecology, "I. Cantacuzino" Clinical Hospital, Bucharest, Romania; \\ ${ }^{3}$ Department of Visceral Surgery, "Fundeni" Clinical Institute, Bucharest, Romania; \\ ${ }^{4}$ Department of Surgery, "Ponderas" Academic Hospital, Bucharest, Romania; \\ ${ }^{5}$ Department of Visceral Surgery, "I. Cantacuzino" Clinical Hospital, Bucharest, Romania; \\ ${ }^{6}$ Department of Internal Medicine, "Fundeni" Clinical Institute, Bucharest, Romania; \\ 7 "Titu Maiorescu" University of Medicine and Pharmacy, Bucharest, Romania
}

\begin{abstract}
Background/Aim: During the last decade it has been widely demonstrated that venous involvement in pancreatic head cancer is not a sign of poor prognostic, while surgery with curative intent is feasible and with encouraging results. However, the location and extent of venous invasion can occasionally pose serious problems in terms of reconstruction. The aim of the paper is to describe a case in which total superior mesenteric and portal vein resection followed by reconstruction were successfully performed. Case Report: We present the case of a 74-year-old patient submitted to surgery for locally advanced pancreatic cancer invading the portal and superior mesenteric veins. Surgery consisting of pancreatoduodenectomy en bloc with portal vein and superior mesenteric vein resection was performed. The venous axis was reconstructed by using a venous cadaveric allograft originating from the external iliac vein. The postoperative outcome was favorable and the histopathological studies confirmed the local invasion of the resected venous structures. Conclusion: The cadaveric venous allograft can be safely used in order to reconstruct the venous axis following extended vascular resections for pancreatic cancer.
\end{abstract}

This article is freely accessible online.

*These Authors contributed equally to this study.

Correspondence to: Irina Balescu, "Ponderas" Academic Hospital, Nicolae Caramfil 85a Street, 014142 Bucharest, Romania. Tel: +40 724077709, e-mail: irina.balescu@ ponderas-ah.ro

Key Words: Superior mesenteric vein, portal vein, pancreatoduodenectomy, cadaveric allograft.
Pancreatic cancer remains one of the most lethal malignancies worldwide, and is associated with extremely poor rates of long-term survival (1-3). In such cases, the most efficient therapeutic strategy remains surgery with curative intent, with important benefits in terms of survival reported in cases of radical resections $(2,4)$. An interesting topic of great debate concerns vascular resections in locally invasive pancreatic tumors. During the last decade evaluation of the presence of venous invasion has shown that it is no longer considered as a contraindication for resections. Similar outcomes have been reported following standard pancreatoduodenectomy and venous resections in association with pancreatoduodenectomy $(4,5)$. However, in such cases, reconstruction of the venous axis can be considered as a real challenge, due to the length of the resected segment. The aim of this paper is to report a case in which invasion of the whole length of the superior mesenteric vein and portal vein imposed performing an extended vascular resection followed by reconstruction with cadaveric allograft.

\section{Case Report}

We present the case of 74-year-old patient submitted to surgery for locally advanced pancreatic cancer in whom an extended portal vein and superior mesenteric vein was needed. In order to reestablish the continuity of the venous flow, we used a cadaveric allograft was used.

The 74-year-old patient was investigated for diffuse abdominal pain, jaundice and $12 \mathrm{~kg}$ weight loss during the last three months. The preoperative computed tomography revealed the presence of a large pancreatic head tumor measuring $4 / 3 / 3 \mathrm{~cm}$ in close contact with the portal and 
superior mesenteric veins. The patient was submitted to surgery, where the local invasion of the portal and superior mesenteric veins was confirmed. Moreover, the venous invasion was present inferiorly up to the level of the mesenteric route and superiorly up to the portal bifurcation. Due to portal invasion, a significant degree of portal hypertension associated with venous dilatation of the jejunal veins was present. As a consequence, the patient was submitted to curative resection consisting of pancreatoduodenectomy en bloc together with partial portal vein and superior mesenteric vein resection. The continuity of the venous circulation was re-established by placing a cadaveric allograft originating from the right external iliac vein, which was anastomosed with a dilated jejunal vein distally through a side to end anastomosis and with the remnant portal vein at the level of the hepatic pedicle through an end to end anastomosis. The vascular anastomosis was performed using 6-0 polypropylene. Uncoated Non-Absorbable Monofilament Blue 13mm 3/8 Circle Needle Precision suture (Prolene, Johnson and Johnson, New Brunswick, NJ, USA). The digestive reconstruction was performed in a standard manner consisting of a gastro-enteroanastomosis, a pancreaticojejunal anastomosis and a hepatico-jejunal anastomosis (2). A Doppler ultrasound of the reconstructed vascular structures was performed on the first, third and seventh postoperative day, and the patient was discharged on the tenth postoperative day. Heparin treatment of low molecular weight $(1.5 \mathrm{mg} / \mathrm{kg}$ daily, single dose) was maintained for the next two months, with an uneventful outcome.

\section{Discussion}

During the last decades, improvement in imaging, surgical techniques and postoperative management of patients with hepato-bilio-pancreatic malignancies have provided the possibility of performing successful surgical procedures with an increasing complexity (6-9). As a consequence, a significant number of cases which would have been otherwise considered as candidates for palliative treatment only are nowadays submitted to surgery with curative intent (10-13). Despite the technological advances, it has been shown that up to $52 \%$ of patients who benefit from pancreatoduodenectomy also need vascular resection $(4,5,14-16)$.

Although the concept of venous resection is now widely accepted, the optimal method of reconstruction is still under debate, with different methods proposed (17-19). Cases presenting a low degree of venous invasion primary end to end anastomosis or even venorrhaphy have shown good results, while cases presenting more extended venous resections require grafts $(4,5,14-16)$. Concerning the type of grafts, these range from autologous grafts consisting of i) saphenous, ii) superficial femoral, iii) iliac, iv) internal jugular vein or v) even gonadal veins to synthetic grafts, such as polytetrafluoroethylene grafts or arterial cryopreserved allografts $(4,5,20-22)$. The use of venous cadaveric allografts is, on the other hand, rarely reported (23-25). The maximum length of the resected segment required to establish the contiguity by direct anastomosis and not by graft interposition has been strongly debated. Most often it is advocated that the maximum length should range between 3 and $5 \mathrm{~cm},(4,5,11$, 13-16) although certain authors claim that a maximum of 8 $\mathrm{cm}$ can be resected without the need of placing a graft if an adequate liver dissection and mobilization as well as mesentery mobilization can be provided (26). In cases where a graft is needed, recent studies came to demonstrate that using an allograft significantly reduces the risk of postoperative thrombosis of the graft (26). The risk of postoperative thrombosis of the graft in cases in which synthetic grafts are used has been also demonstrated in the study conducted by Gao et al. (27). In the paper published by this team in 2016, the authors included 62 patients submitted to direct reconstruction of the portal vein and seven cases submitted to reconstruction using a synthetic allograft. They demonstrated that the rate of venous thrombosis was of $16.7 \%$ among the first group and $85.7 \%$ among the second group; moreover, although it was not statistically significant, patients included in the first group reported a higher median overall survival; however, this fact was probably related to a lower extension of the disease (27).

One of the largest studies which were focused on the subject of cadaveric venous allografts used for mesentericoportal reconstruction after pancreatoduodenectomy was published by the Norwegian team led by Kleive in 2016 (25). The study included 45 patients submitted to venous reconstruction of portal and superior mesenteric vein continuity by using cadaveric venous allografts; among these cases there were 16 patients who developed severe postoperative complications, reoperation being needed in four cases while intraoperative mortality was further reported in two cases (25).

Another interesting study which demonstrated the safety and effectiveness of the method in short term and long term outcomes was published by Wang et al. and included 42 cases submitted to pancreatoduodenectomy en bloc with venous resections and 166 cases submitted to standard pancreatoduodenectomy (26). Among these cases, the authors underlined the fact that whenever the extent of the resected segment of the portal vein was lower than $4 \mathrm{~cm}$ a direct end to end, tension free anastomosis was feasible while in cases presenting longer than $4 \mathrm{~cm}$ venous segment resections, an allograft was used. In certain cases a similar situation to the one reported in our case was encountered, a similar reconstruction using an end-to-side anastomosis between the allograft and a dilated jejunal vein being performed. As for the type of allograft, fresh harvested blood vessels less than 24 hours were the option of choice, followed by frozen blood vessels when fresh vessels were 


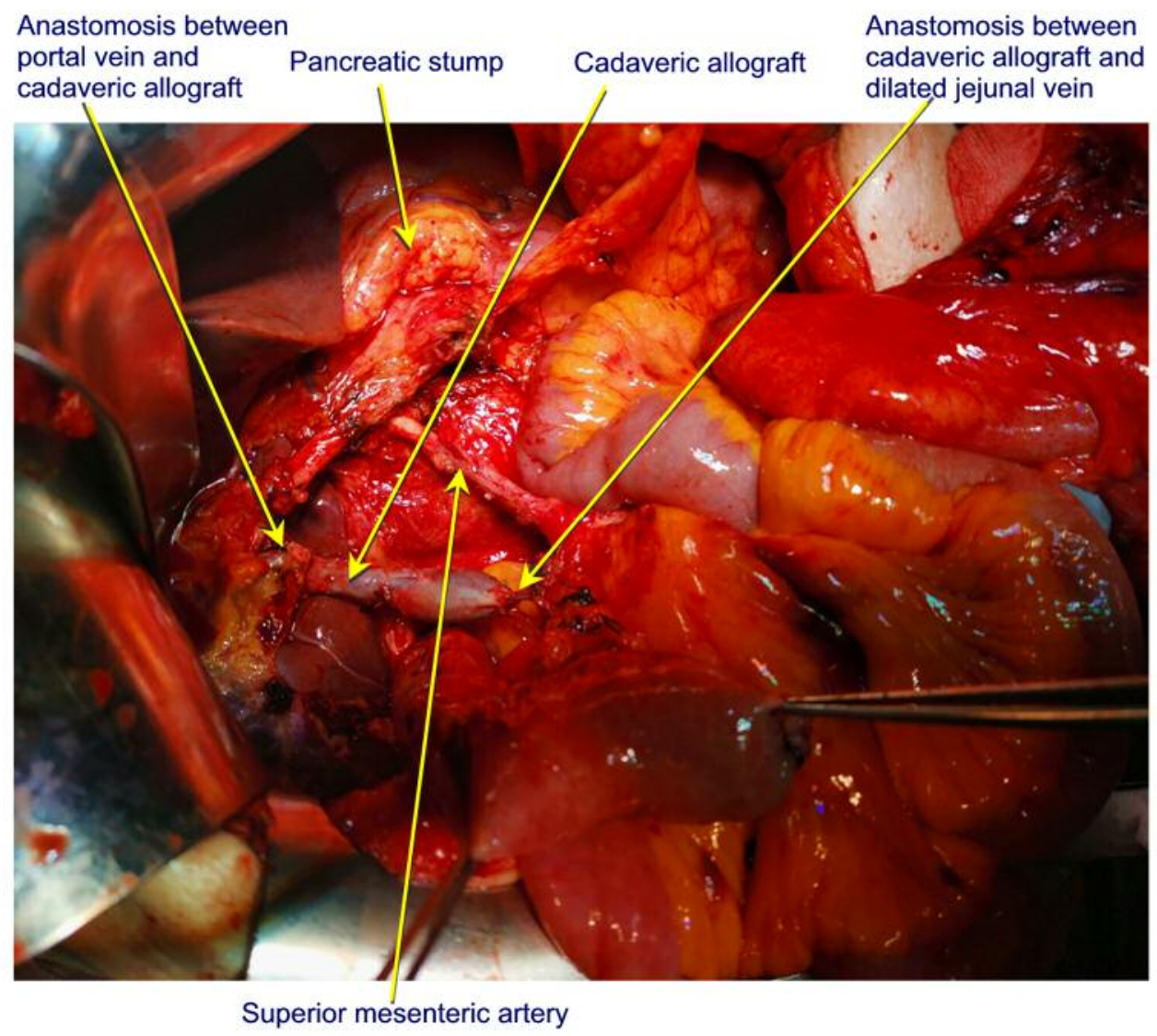

Figure 1. The final aspect after pancreatoduodenectomy en bloc with portal and superior mesenteric vein resection and reconstruction using a cadaveric graft consisting of external iliac vein.

not available. Similar rates of pancreatic related surgery complications were encountered between the two groups (including pancreatic leaks, hemorrhage, delayed gastric emptying or abdominal abscesses) while the 30 days and 90 days postoperative mortality rates were also similar between cases submitted to standard pancreatoduodenectomy versus pancreatoduodenectomy en bloc with venous resection and reconstruction. Moreover, survival analysis reported similar rates of one year, two and three year survivals as well as similar median overall survival rates. When an analysis of factors influencing survival was performed, poor prognostic factors for the long term outcomes were represented by the degree of tumoral differentiation, tumor size, radicality of resection and advanced TNM stage at surgery. Another interesting aspect demonstrated by this study was the one regarding prognostic factors for portal vein invasion; therefore the study came to demonstrate that association of lumbar pain preoperatively, pancreatic capsular invasion, bile duct infiltration or tumor juxtaposition on the portal vein; all these data came to demonstrate once again that the presence and the extent of venous invasion should not preclude performing surgery with radical intent (26).

As for the prognostic value of the resected length of the venous system, a Japanese team led by Kaneoka, have published a paper in which they demonstrated that the best long-term outcomes are to be expected if the resected venous length does not surpass $3 \mathrm{~cm}$, with a five year survival rate at $39 \%$ among cases presenting a limited venous invasion and at $4 \%$ in cases presenting a longer than $3 \mathrm{~cm}$ zone of venous invasion, irrespective of whether it involves direct reconstruction or allograft placement (28).

Venous invasion in pancreatic head cancer is no longer a contraindication for resection, with similar long-term outcomes reported following resection of such lesions and compared to standard pancreatoduodenectomy. However, an ongoing debate is reported in terms of reconstruction; while cases presenting a limited invasion are usually submitted to a direct reconstruction through end to end anastomosis, cases in which larger venous resections are needed might be candidates for different types of reconstruction. Although 
synthetic grafts were initially introduced with acceptable results, they proved to be associated with a significant risk of thrombosis and are being replaced with cadaveric venous allografts whenever possible, improving the outcomes of the patients. The method of using cadaveric allografts plays a crucial role especially in cases in which an extended venous resection is needed as in the case we have presented here.

\section{Conflicts of Interest}

None.

\section{Authors' Contributions}

IP, VB, NB performed the surgical procedure; MV and SD reviewed literature data; IB, LI prepared the draft of the manuscript; IB and IP were advisors of the surgical oncology procedures. IP reviewed the final version of the manuscript. All Authors read and approved the final version of the manuscript.

\section{Acknowledgements}

This work was supported by the project entitled „Multidisciplinary Consortium for Supporting the Research Skills in Diagnosing, Treating and Identifying Predictive Factors of Malignant Gynecologic Disorders", project number PN-III-P1-1.2-PCCDI2017-0833.

\section{References}

1 Liles JS and Katz MH: Pancreaticoduodenectomy with vascular resection for pancreatic head adenocarcinoma. Expert Rev Anticancer Ther 14: 919-929, 2014. PMID: 24833085. DOI: $10.1586 / 14737140.2014 .919860$

2 Bockhorn M, Uzunoglu FG, Adham M, Imrie C, Milicevic M, Sandberg AA, Asbun HJ, Bassi C, Buchler M, Charnley RM, Conlon K, Cruz LF, Dervenis C, Fingerhutt A, Friess H, Gouma DJ, Hartwig W, Lillemoe KD, Montorsi M, Neoptolemos JP, Shrikhande SV, Takaori K, Traverso W, Vashist YK, Vollmer C, Yeo CJ and Izbicki JR: Borderline resectable pancreatic cancer: a consensus statement by the International Study Group of Pancreatic Surgery (ISGPS). Surgery 155: 977-988, 2014. PMID: 24856119. DOI: 10.1016/j.surg.2014.02.001

3 Zhou Y, Zhang Z, Liu Y, Li B and Xu D: Pancreatectomy combined with superior mesenteric vein-portal vein resection for pancreatic cancer: a meta-analysis. World J Surg 36: 884-891, 2012. PMID: 22350478. DOI: 10.1007/s00268-012-1461-z

4 Brasoveanu V, Anghel C, Barbu I, Pautov M, Ionescu MI, Motthor M, Balescu I, Dima S and Bacalbasa N: Pancreatoduodenectomy en bloc with portal and superior mesenteric artery resection - a case report and literature review. Anticancer Res 35: 1613-1618, 2015. PMID: 25750318.

5 Brasoveanu V, Dumitrascu T, Bacalbasa N and Zamfir R: Splenic artery used for replaced common hepatic artery reconstruction during pancreatoduodenectomy - a case report. Chirurgia (Bucur) 104: 499-504, 2009. PMID: 19886062.

6 Iliescu L, Mindrut E, Grasu M, Orban C, Tanase A and Toma L: Management of hepatocellular carcinoma - experience of a single center. Chirurgia (Bucur) 109: 204-207, 2014. PMID: 24742411.
7 Bacalbasa N, Taras C, Orban C, Iliescu L, Hurjui I, Hurjui M, Niculescu N, Cristea $\mathrm{M}$ and Balescu I: Atypical right hepatectomy for liver metastasis from ovarian leiomyosarcoma A case report and literature review. Anticancer Res 36: 18351840, 2016. PMID: 27069167.

8 Pascu O, Voiculescu M, Gheorghe L, Micu L, Seicean A, Iliescu L, Mocan T, Ceausu E and Mateescu B: Early virological response in 1220 patients with $\mathrm{HCV}$ (genotype lb) chronic hepatitis and cirrhosis treated with PegInterferon plus Ribavirin. Rom J Intern Med 49: 105-112, 2011. PMID: 22303601.

9 Iliescu L, Ioanitiescu S, Toma L and Orban C: Spontaneous portohepatic venous shunt: ultrasonographic aspect. Ultrasound Q 31: 141-144, 2015. PMID: 25734334. DOI: 10.1097/RUQ.0 000000000000148

10 Iliescu L, Toma L, Mercan-Stanciu A, Grumeza M and Ioanitescu S: Contrast-enhanced ultrasonography in the diagnosis of portal vein thrombosis: A pictorial review. Ultrasound Q, 2019. PMID: 31083039. DOI: 10.1097/RUQ.0000000000000451

11 Bacalbasa N, Balescu I, Tanase A, Pautov M, Brezean I, Vilcu $\mathrm{M}$ and Brasoveanu V: Spleno-pancreatectomy en bloc with parcelar gastrectomy for splenic artery aneurysm - A case report and literature review. In Vivo 32: 915-919, 2018. PMID: 29936480. DOI: 10.21873/invivo.11329

12 Bacalbasa N, Balescu I, Tanase A, Brezean I, Vilcu M and Brasoveanu V: Successful resection of a non-functional paraganglioma with celiac trunk invasion followed by common hepatic artery reimplantation - A case report and literature review. In Vivo 32: 911-914, 2018. PMID: 29936479. DOI: 10.21873/invivo.11328

13 Brezean I, Catrina E, Aldoescu S, Rahimi M, Manescu D, Veranu I and Radulescu D: ["The fate" of a peri-cysticjejunostomy in the treatment of the hydatid liver cysts]. Chirurgia (Bucur) 101: 81-82, 2006. PMID: 16623382.

14 Brezean I, Aldoescu S, Catrina E, Fetche N, Marin I and Pacescu E: Gallstone ileus: analysis of eight cases and review of the literature. Chirurgia (Bucur) 105: 355-359, 2010. PMID: 20726301.

15 Bacalbasa N, Brezean I, Anghel C, Barbu I, Pautov M, Balescu I and Brasoveanu V: Successful resection and vascular ligation of a large hepatic artery aneurysm - A case report and literature review. In Vivo 31: 979-982, 2017. PMID: 28882969.

16 Bacalbasa N, Brezean I, Anghel C, Barbu I, Pautov M, Balescu $\mathrm{I}$ and Brasoveanu V: Management of a fulminant upper gastrointestinal bleeding exteriorized through hemobilia due to arteriobiliary fistula between the common bile duct and a right hepatic artery aneurysm - A case report. In Vivo 31: 983-989, 2017. PMID: 28882970.

17 Samra JS, Bachmann RA, Choi J, Gill A, Neale M, Puttaswamy V, Bell C, Norton I, Cho S, Blome S, Maher R, Gananadha S and Hugh TJ: One hundred and seventy-eight consecutive pancreatoduodenectomies without mortality: role of the multidisciplinary approach. Hepatobiliary Pancreat Dis Int 10: 415-421, 2011. PMID: 21813392.

18 Martin RC, Scoggins CR, Egnatashvili V, Staley CA, McMasters $\mathrm{KM}$ and Kooby DA: Arterial and venous resection for pancreatic adenocarcinoma: operative and long-term outcomes. Arch Surg 144: 154-159, 2009. PMID: 19221327. DOI: 10.1001/archsurg.2008.547

19 Carrere N, Sauvanet A, Goere D, Kianmanesh R, Vullierme MP, Couvelard A, Ruszniewski $\mathrm{P}$ and Belghiti J: Pancreaticoduodenectomy with mesentericoportal vein resection for 
adenocarcinoma of the pancreatic head. World J Surg 30: 15261535, 2006. PMID: 16855797. DOI: 10.1007/s00268-005-0784-4

20 Yamamoto Y, Sakamoto Y, Nara S, Ban D, Esaki M, Shimada K and Kosuge T: Reconstruction of the portal and hepatic veins using venous grafts customized from the bilateral gonadal veins. Langenbecks Arch Surg 394: 1115-1121, 2009. PMID: 19421769. DOI: $10.1007 /$ s00423-009-0500-1

21 Chu CK, Farnell MB, Nguyen JH, Stauffer JA, Kooby DA, Sclabas GM and Sarmiento JM: Prosthetic graft reconstruction after portal vein resection in pancreaticoduodenectomy: a multicenter analysis. J Am Coll Surg 211: 316-324, 2010. PMID: 20800187. DOI: 10.1016/j.jamcollsurg.2010.04.005

22 Mascoli C, D'Ambra M, Casadei R, Ricci C, Taffurelli G, Ancetti S, Stella A, Minni F and Freyrie A: Portal/superior mesenteric vein reconstruction during pancreatic resection using a cryopreserved arterial homograft. Dig Surg 32: 284-290, 2015. PMID: 26113314. DOI: 10.1159/000381194

23 Meniconi RL, Ettorre GM, Vennarecci G, Lepiane P, Colasanti M, Laurenzi A, Colace L and Santoro R: Use of cold-stored vein allografts for venous reconstruction during pancreaticoduodenectomy. J Gastrointest Surg 17: 1233-1239, 2013. PMID: 23615805. DOI: $10.1007 / \mathrm{s} 11605-013-2201-\mathrm{x}$

24 Zhang Q, Yan S, Wang W, Shen Y, Zhang M, Ding Y and Zheng $S$ : Use of allograft for portomesenteric vein interposition in radical resection of pancreatic tumor. Surg Pract 17: 22-27, 2013. PMID: 29113411. DOI: 10.18632/oncotarget.20866
25 Kleive D, Berstad AE, Verbeke CS, Haugvik SP, Gladhaug IP, Line PD and Labori KJ: Cold-stored cadaveric venous allograft for superior mesenteric/portal vein reconstruction during pancreatic surgery. HPB (Oxford) 18: 615-622, 2016. PMID: 27346143. DOI: 10.1016/j.hpb.2016.05.010

26 Wang WL, Ye S, Yan S, Shen Y, Zhang M, Wu J and Zheng SS: Pancreaticoduodenectomy with portal vein/superior mesenteric vein resection for patients with pancreatic cancer with venous invasion. Hepatobiliary Pancreat Dis Int 14: 429-435, 2015. PMID: 26256089.

27 Gao W, Dai X, Dai C, Jiang K, Wu J, Li Q, Guo F, Chen J, Wei $\mathrm{J}, \mathrm{Lu} \mathrm{Z}, \mathrm{Tu} \mathrm{M}$ and Miao Y: Comparison of patency rates and clinical impact of different reconstruction methods following portal/superior mesenteric vein resection during pancreatectomy. Pancreatology 16: 1113-1123, 2016. PMID: 27707648. DOI: 10.1016/j.pan.2016.09.010

28 Kaneoka Y, Yamaguchi A and Isogai M: Portal or superior mesenteric vein resection for pancreatic head adenocarcinoma: prognostic value of the length of venous resection. Surgery 145: 417-425, 2009. PMID: 19303991. DOI: 10.1016/j.surg.2008.12.009

Received October 28, 2019

Revised November 9, 2019

Accepted November 18, 2019 